Article

\title{
Characterizing New Channels of Communication: A Case Study of Municipal 311 Requests in Edmonton, Canada
}

\author{
Qing $\mathrm{Lu} *$ and Peter A. Johnson \\ Department of Geography and Environmental Management, University of Waterloo, Waterloo, N2J 4A8, Canada; \\ E-Mails: q25lu@uwaterloo.ca (Q.L.), peter.johnson@uwaterloo.ca (P.J.) \\ * Corresponding author
}

Submitted: 11 March 2016 | Accepted: 10 May 2016 | Published: 7 June 2016

\begin{abstract}
City governments around the world are developing and expanding how they connect to citizens. Technologies play an important role in making this connection, and one frequent way that cities connect with citizens is through 311-style request systems. 311 is a non-emergency municipal notification system that uses telephone, email, web forms, and increasingly, mobile applications to allow citizens to notify government of infrastructure issues and make requests for municipal services. In many ways, this process of citizen contribution mirrors the provision of volunteered geographic information, that is spatially-referenced user generated content. This research presents a case study of the city of Edmonton, Canada, an early adopter of multi-channel 311 service request systems, including telephone, email, web form, and mobile app 311 request channels. Three methods of analysis are used to characterize and compare these different channels over three years of request data; a comparison of relative request share for each channel, a spatial hot spot analysis, and regression models to compare channel usage with sociodemographic variables. The results of this study indicate a shift in channel usage from traditional to Internet-enabled, that this shift is mirrored in the hotspots of request activity, and that specific digital inequalities exist that reinforce this distinction between traditional and Internetenabled reporting channels.
\end{abstract}

\section{Keywords}

311; digital divide; mobile app; municipal government; open data; VGI

\section{Issue}

This article is part of the issue "Volunteered Geographic Information and the City", edited by Andrew Hudson-Smith (University College London, UK), Choon-Piew Pow (National University of Singapore, Singapore), Jin-Kyu Jung (University of Washington, USA) and Wen Lin (Newcastle University, UK).

(C) 2016 by the authors; licensee Cogitatio (Lisbon, Portugal). This article is licensed under a Creative Commons Attribution 4.0 International License (CC BY).

\section{Introduction}

In recent years, spatial data has shifted from being created by paid, highly-skilled individuals, using specialized equipment, to non-expert creation (Goodchild, 2007a). This contribution of volunteered geographic information (VGI), or spatial data that is reflective of individual experience and assertion (Goodchild, 2007a), is changing the way that spatial data is collected. These non-experts, who may be contributing spatial information in their leisure time, and for a variety of reasons, are often referred to as neogeographers (Turner,
2006). Rapid advances in mobile and web-based technology is a significant facilitator of the increase in VGI (Haklay, 2013). The increased accuracy and reduced cost of Global Positioning Systems (GPS) receivers, rising availability of smartphones, and the wide spread of wireless networks have made geographic information readily obtained by handheld devices (Goodchild, 2007a; Jiang \& Yao, 2006). Further, the growing demand for geographic information is also a contributing factor of VGI; in-vehicle navigation, travel planning and real-estate businesses all rely on geographic information to provide services to customers, and these lo- 
cation-based services have filtered into many aspects of everyday life (Elwood, Goodchild, \& Sui, 2012).

A current trend in VGI generation is for citizens to support their local government in collecting information to facilitate planning and decision-making (Sæbø, Rose, \& Flak, 2008). The adoption of VGI in the public sector can be conceived as a branch of egovernment initiatives, and it expands e-government from one-way "government-to-citizen" (G2C) service delivery to two-way "citizen-to-government-to-citizen" (C2G2C) conversation (Johnson \& Sieber, 2013; Sieber \& Johnson, 2015). This bottom-up information production process can provide government with up-to-date and small-scale spatial information at low cost (Goodchild, 2007a). As citizens are closer to a phenomena and hold local knowledge that government agencies may not possess, citizens act as environmental sensors producing rich information and data that can be incorporated into management and decision-making (Goodchild, 2007b; Johnson \& Sieber, 2013). The process of providing services based on citizen-generated information also impacts the relationship between government and citizens by enhancing transparency, responsiveness and accountability of governments (Wong \& Welch, 2004).

Municipal 311 service, typically a direct call line or web portal, is one example of how citizens can use VGI to contribute feedback to government (Elwood et al., 2012). First implemented in Baltimore, U.S., this 311 system was initially established to alleviate 911 service congestion caused by large volume of non-emergency calls (Schwester, Carrizales, \& Holzer, 2009). With the prevalence of the Internet and smartphones, phone calls are no longer the only channel that 311 services source reports from. Rather, web forms, emails and mobile apps have been developed to create additional platforms for citizens to contact the government (DeMeritt, 2011). With this rise in the variety of 311 service channels, it is critical to conduct a characterization of these methods and their use in a real-world context. With multiple 311 channels available, is there a dominant channel that is favored compared to others, and how has that channel mix changed over time and with the introduction of new channels, such as mobile apps? Are there geographic concentrations of 311 reports and do these differ by channel? And lastly, building on work done by Cavallo, Lynch and Scull (2014), are there demographic relationships with 311 channel use, highlighting existing digital divides? To answer these questions, this paper presents a case study of citizen contributions made using a 311 service in the City of Edmonton, Canada. As one of Canada's leading 'open' municipalities (both in terms of providing open data and establishing open government policies), Edmonton makes a suitable case study for tracing the development and deployment of 311 systems, providing lessons for other municipal governments currently con- sidering or rolling out similar systems. 311 requests from 2013 to 2015 are analyzed and interpreted to identify changes in citizens' usage of multiple reporting channels, and to determine spatial patterns and hotspots of requests within the City of Edmonton. Lastly, 311 requests and channels are compared to relevant demographic variables to indicate if there are connections between residential demographics and 311 reporting.

\section{The Rise of Citizen Contribution of VGI in Government}

Incorporating local knowledge into urban planning and management is not a new idea. Public participation GIS (PPGIS) was initiated in the 1990s, and it refers to the use of GIS to support public participation in planning, management and decision making (Ganapati, 2011; Sieber, 2006). Technologies that enable PPGIS have evolved from traditional desktop-based GIS to Web GIS and to Geospatial Web 2.0 platforms over the past two decades (Ganapati, 2010). In addition, the increasing availability of open GIS software has removed the costs associated with installing proprietary software, which also contributes to the expansion of PPGIS (Hall, Chipeniuk, Feick, Leahy, \& Deparday, 2010). Since its emergence, PPGIS has been applied in numerous areas, from "community and neighbourhood planning to environmental and natural resource management to mapping traditional ecological knowledge of indigenous people" (Brown, 2012, p.2).

The term VGI was proposed almost a decade after PPGIS was developed (Goodchild, 2007a). VGI and PPGIS are related as both of the terms feature collecting and using spatial information from non-experts (Brown \& Kyttä, 2014). Tulloch (2008) argues that VGI shares common foundations with PPGIS in that both involve investigating and identifying locations that are important to individuals. Brown and Kytta (2014) compared VGI with PPGIS in terms of process emphasis, sponsors, place context, importance of mapped data quality, sampling approach, data collection, data ownership and dominant mapping technology. They pointed out that the process of PPGIS emphasizes enhancing public involvement to inform land use planning and management sponsored by government planning agencies, while VGI focuses on expanding the collection of spatial information through citizens acting as sensors, sponsored by NGOs, ad hoc groups, or individuals. In addition, Lin suggested that individuals are more likely to utilize public datasets when participating in decision-making processes in PPGIS while individuals create their own data in the context of VGI (Lin, 2013). The casualness and entertainment features in VGI are also distinct from the ways that PPGIS traditionally theorizes participation (Lin, 2013). However, the lines between VGI and PPGIS are not always clear, as Tulloch 
(2008) argues that some volunteers involved in VGI have a tendency to participate in the process of decision making when creating and sharing spatial information.

PPGIS and VGI are suggested to have potential for supporting e-government initiatives, which refer to "the delivery of information and services online through the Internet and other digital means" (Ganapati, 2011; West, 2004, p.2). Moon (2002) proposed an e-government model with five stages, with political participation considered as the highest stage, suggesting that some technologies could promote public participation by enhancing two-way communications between government and citizens. PPGIS and VGI that use Web 2.0 technology can enable individuals to create spatial data and to participate in the decision-making process (Rinner, Keßler, \& Andrulis, 2008). Johnson and Sieber (2013) also argue that VGI is valuable to government in providing an opportunity for citizens to collaborate on achieving social, economic, and environmental goals. Cavallo et al. (2014) suggest that the modern 311 services that provide multiple channels for citizens to report problems or complaints can be regarded as a method of direct connection with local governments, and provide citizens with the appropriate means of making contributions to community issues.

As individuals possess local knowledge that is not necessarily represented in traditional authoritative data, they can act as intelligent sensors of their surroundings and collect accurate and timely information (Goodchild, 2007b). Goodchild also points out that this method of collecting information can be much more cost-effective compared to traditional ways of collecting data that involve expensive equipment and highly-paid experts. In addition, the widespread availability of smartphones, location-based services (LBS) and social networks facilitate the creation and sharing of geographic information in real time (Chon \& Cha, 2011; Goodchild \& Glennon, 2010). These features of VGI imply great potential, as the location information attached to 311 reports can be visualized and analyzed to improve urban planning, management and operations processes, particularly to reveal issues that may not be detected using conventional methods, such as dead animals and unusual odors (Johnson, 2010; Naphade, Banavar, Harrison, Paraszczak, \& Morris, 2011; Offenhuber, 2014).

The adoption of VGI is facing challenges despite the aforementioned values and benefits. Created by amateurs, there is no assurance of quality in VGI (Goodchild \& Li, 2012). Cooper et al. (2011) suggest that the quality of VGI should be assessed through aspects of positional accuracy, attribute accuracy, currency, completeness, logical consistency and lineage, but the nature of VGI poses challenges for assessing its quality in these ways, as they argue VGI can be subjective, with quality dependent on the data user, purpose, and the context in which it is used. Further, Coleman, Georgiadou and Labonte (2009) proposed that the motivations of VGI contributors could affect the data quality, with biased information potentially being contributed knowingly.

Another critical concern about adoption of VGI in government are digital inequalities, such as uneven levels of access to computers and the Internet across a society (Compaine, 2001). Many studies focus on digital inequalities in the global context which suggests the gaps in the access to the Internet and other advanced technologies between developed and developing countries (Genovese \& Roche, 2010; Goodchild, 2007a; Sui, Goodchild, \& Elwood, 2013). However, digital inequalities also exist at small geographical levels. Thomas and Streib (2003) conducted a survey in the state of Georgia in the U.S. and found that the use of the Internet is associated with income, education level, age, race and place of residence; those who have higher incomes or education levels tend to use the Internet more than those who have lower incomes or education levels; younger people show higher Internet use than older people; whites and local residents are higher in Internet use than non-whites or non-locals. Similarly, Bélanger and Carter (2009) carried out a survey to explore the relationships between demographic characteristics and the use of e-government services; the results show that income, education level, age and frequency of Internet use affect the use of egovernment services. Cavallo et al. (2014) conducted a case study to determine the relationships between sociodemographic status and 311 service request frequency by developing a linear regression model, and their results indicate that demographic profile plays an important role in e-government participation.

\section{City of Edmonton Case Study}

\subsection{Study Area}

The city of Edmonton, the capital city of the Canadian province of Alberta, is the study area for this research (Figure 1). Edmonton had a population of 1,206,040 in 2011, making it Canada's fifth-largest municipality (Statistics Canada, 2015a). The City of Edmonton offers 311 services for citizens to request information and for non-emergency services such as pothole reporting, drainage maintenance, and dead animal removal. Edmonton's 311 service is available through four different channels; telephone, web form, email, and a mobile app called Edmonton 311 (for both Android and iOS operating systems). The multiple 311 channels offered by the City of Edmonton make it an appropriate case study for the collection of VGI in the public sector, serving as an example to other municipalities that may be considering similar types of systems. Three methods of analysis are used on the City of Edmonton 311 re- 
quest data; first, a characterization of request channels, second, a hot spot analysis to determine geographic areas of high request activity, and last, an analysis of channel use compared to sociodemographic data of area residents.

\subsection{Characterization of 311 Requests}

The City of Edmonton (n.d.) maintains an open data portal where all 311 service request data is provided for free public download in various formats. Each request record contains information such as date reported, request status, service category, ticket source (the channel from which a request is made), and longitude and latitude of the reported issue (Table 1). For this research, all the service requests from January 1, 2013 to December 31, 2015 were retrieved, a total of 178,691 requests.

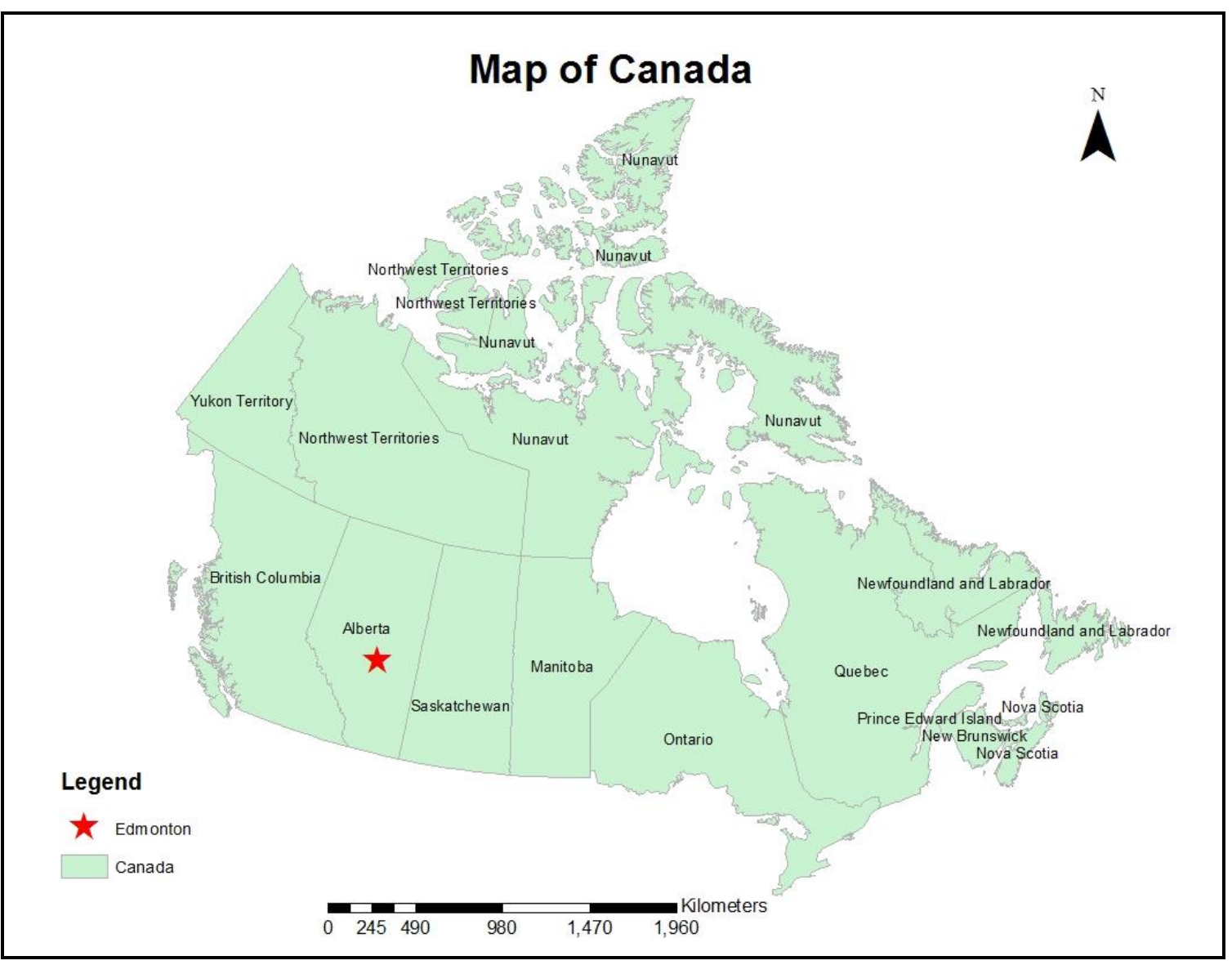

Figure 1. Map of Canada showing Edmonton.

Table 1. An example of 311 request record in open data catalogue.

\begin{tabular}{|c|c|c|c|}
\hline Ticket Number & 8013549449 & Ward & Ward 07 \\
\hline Date Created & May 20, 2015 & Address & 1210980 STREET NW \\
\hline Date Closed & May 21, 2015 & Lat & 53.5754544171464 \\
\hline Request Status & Closed & Long & -113.463358322629 \\
\hline Status Detail & $\begin{array}{l}\text { Assessed-No Action } \\
\text { Required }\end{array}$ & Location & $\begin{array}{l}\text { (53.5754544171464, - } \\
113.463358322629)\end{array}$ \\
\hline Service Category & Tree Maintenance & Ticket Source & Mobile App \\
\hline Service Details & Broken Branches & Calendar & 2015 \\
\hline Business Unit & Forestry & Count & 1 \\
\hline Neighbourhood & EASTWOOD & Posse_Number & $172692468-001$ \\
\hline Community League & $\begin{array}{l}\text { Eastwood Community } \\
\text { League }\end{array}$ & Transit_Ref_Number & 239856 \\
\hline
\end{tabular}


The percentage of requests received from each channel (telephone, email, web form, and mobile app) by month is shown in Figure 2. Percentage share for each channel is used to provide a comparison over time. This analysis shows that the share of telephone calls decreases significantly over time, accounting for $95 \%$ of 311 requests in 2013 to $80 \%$ at the end of 2015 . This change in relative share is driven by the launch of the Edmonton 311 mobile app in November 2014. The Edmonton 311 mobile app capture a $6 \%$ share of requests on launch in November 2014, reaching its peak in April 2015 with $18 \%$ of request share. This percentage decreases after April 2015 and becoming stable at $12 \%$ of all requests. In comparison to these two dominant channels, email and web form requests are smaller components of the 311 request mix, with email representing $5 \%$ of requests and web form representing $7 \%$ of requests. It is noted that though the share of telephone requests has decreased significantly since the launch of web form and mobile app channels, it still remains the main channel for citizens to make 311 requests, with approximately $80 \%$ of all requests, compared to $20 \%$ for the combined Internet-based methods of mobile app, email, and web form.

The volume of requests by month is shown in Figure 3. The number fluctuates notably over time; the highest value of about 140,000 is observed in January 2014, and the lowest value occurred in December 2015 , which is around 1,800. Although the volume is not constant, some similarities are seen in terms of seasonal changes. For each year, the peak value is seen in winter; the highest value is in March for 2013, in January for 2014, and in March for 2013. In addition, it is noted that the number of requests decrease from July for all the three observation years. May 2014 and November 2014, when the web form and mobile app were launched respectively, did not see significant changes in the volume of requests. For the number of annual requests, it decreased dramatically from 2013 to 2015; about 63,681 requests were reported in 2013, and the number dropped by $15.6 \%$ to 53,723 requests in 2015 . The decreasing total number of requests indicate that the newly-introduced channels did not contribute to more service requests in the City of Edmonton, and the diminishing share of requests by traditional channels imply that users are turning to new channels to make requests.

\subsection{Hot Spot Analysis}

Visualizing the geographic distribution of channel usage can show which areas of Edmonton generate service requests via a particular channel. To avoid spatial visualization issues that are generated from using statistical units that vary in size, the study area is divided into a set of $1 \mathrm{~km}$ by $1 \mathrm{~km}$ grid cells. All request data are aggregated at each grid cell, and the percentage of requests from each channel are calculated for each grid cell. Cells with higher percentages indicate that users in this area are more likely to use a particular channel to submit requests than in other cells. Instead of individual areas with high or low values, spatial clusters of high or low value grids were created using the Hot Spot Analysis tool in ArcGIS. These hot spots are generated by examining the value of each feature and its neighboring features, and a statistically significant hot spot is created where a feature with high value is also surrounded by high-value features (Scott \& Warmerdam, 2005). The Hot Spot Analysis tool in ArcGIS calculates the Getis-Ord Gi* statistic for each feature in the input data, resulting in z-scores (Esri, 2015). For positive zscores, a larger z-score indicates more intense clustering of high values. For negative z-scores, a lower zscore represents more intense clustering of low values. This tool was applied for each channel, generating four hot spot analysis results (Figure 4).

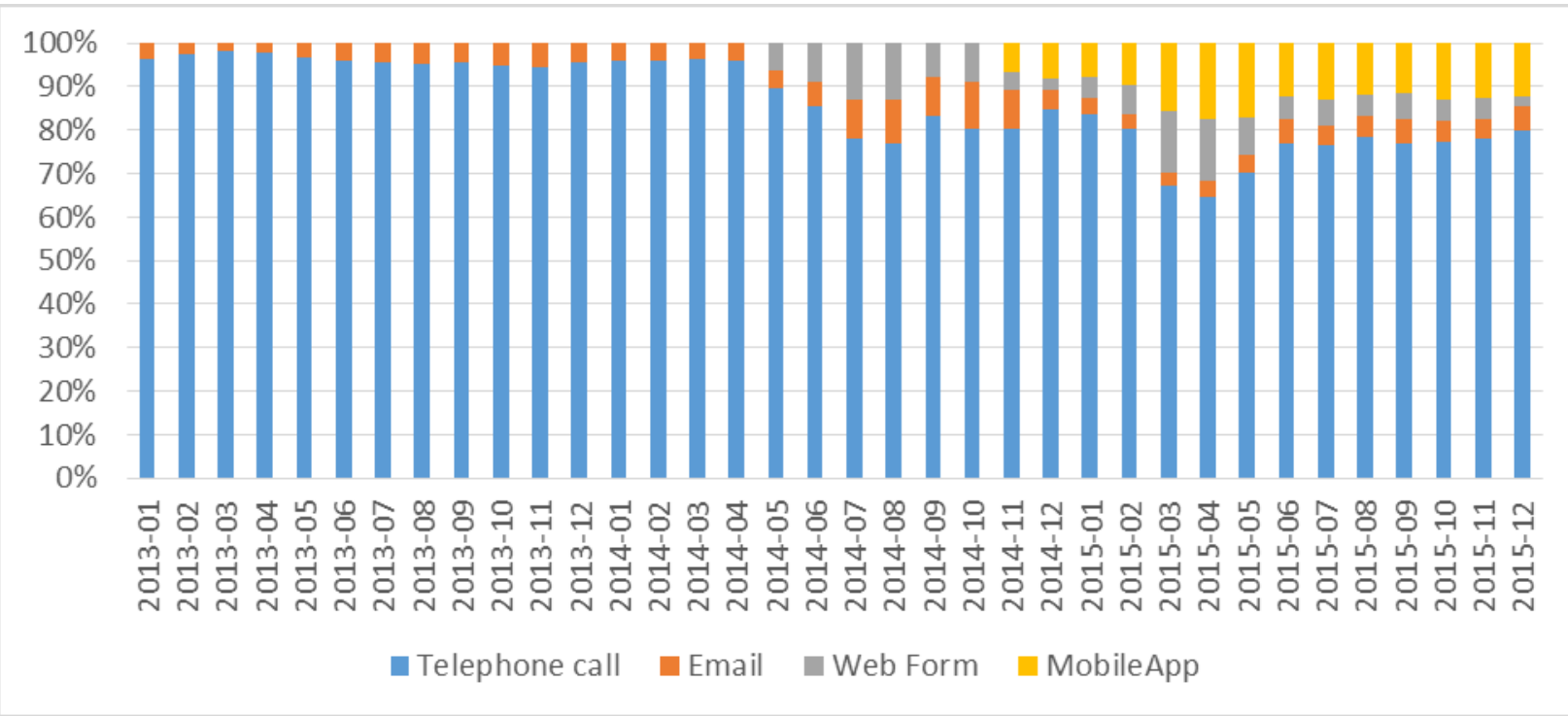

Figure 2. Percentage of requests from channels by month (From January 2013 to December 2015). 


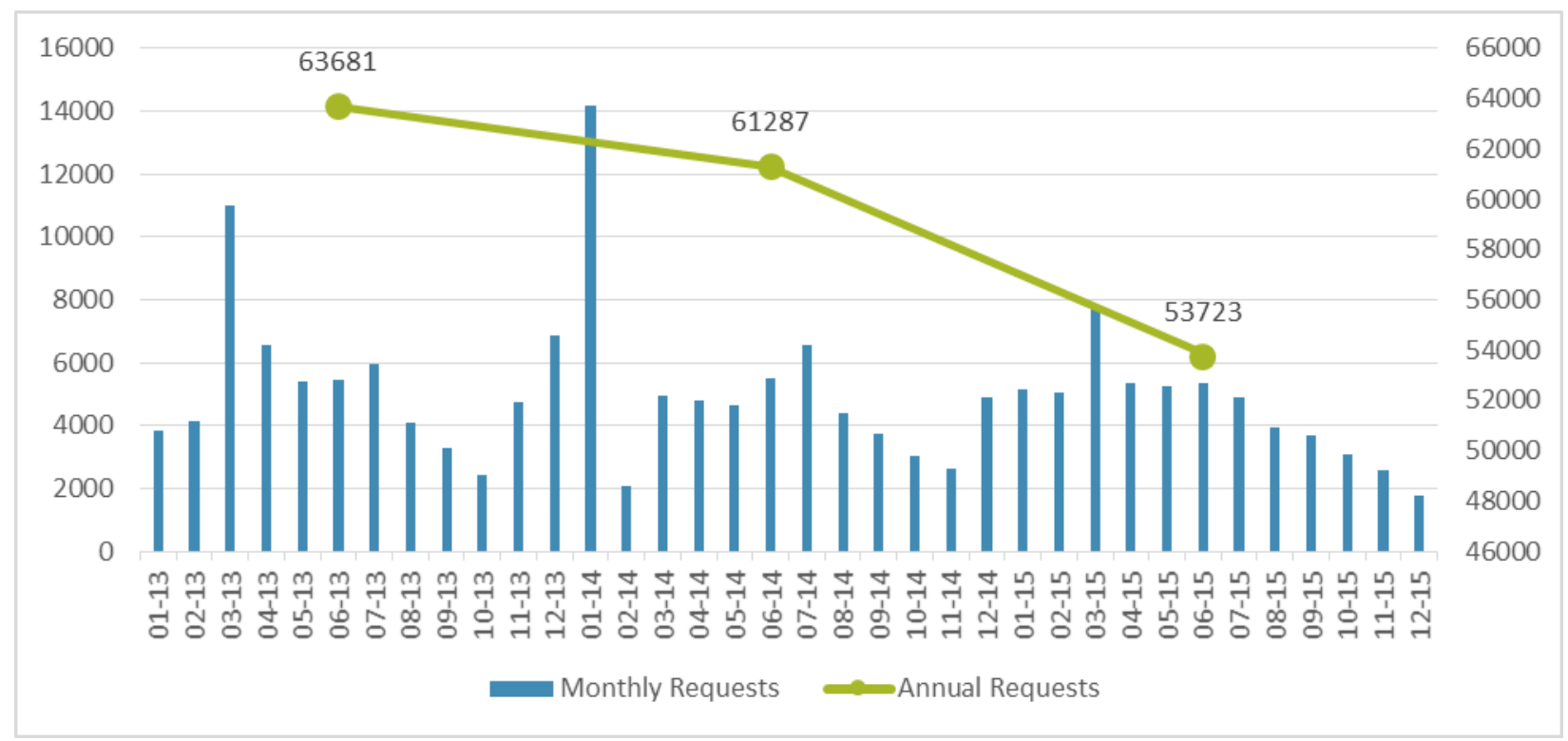

Figure 3. Total number of requests by month (From January 2013 to December 2015).

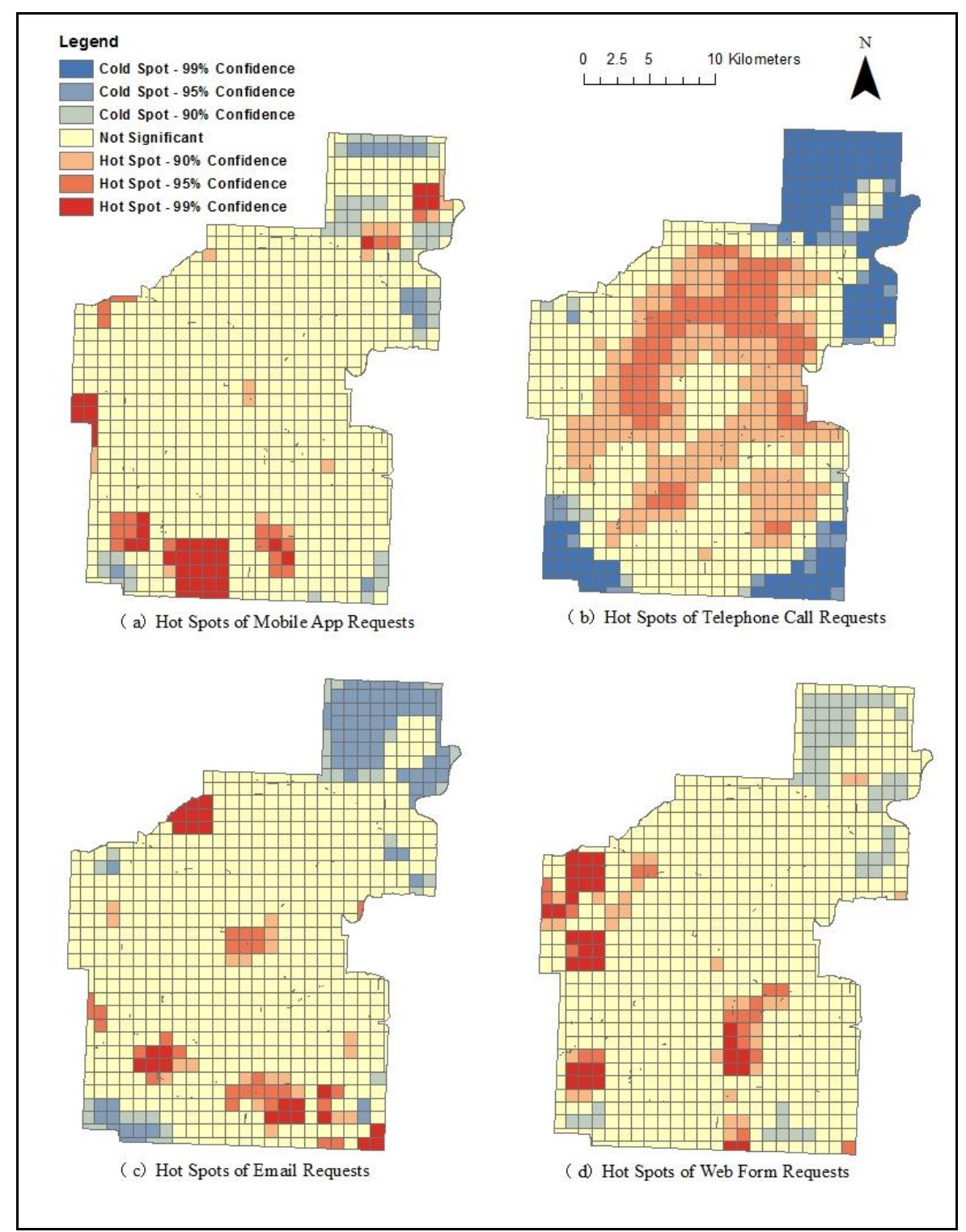

Figure 4. Hot spots analysis results based on percentages of reports from each channel. 
Figure 4 shows the results from this hot spot analysis, based on percentages of requests from each channel instead of absolute numbers of requests from channels. Red indicates hot spots while blue stands for cold spots and yellow indicates no statistical significance. From map (a) which represents the requests from the mobile app channel, hotspots are mainly in the southwest of the city where a combination of agricultural land and residences are located. In contrast, the inner city which has a high density of residences and businesses shows no clustering in terms of percentage of reports received from the mobile app channel. This suggests that mobile app use is randomly distributed in the city center residences. The second map (b), represents requests from telephone calls, and shows hot spots circling the city center, with no significant clustering in the city center itself. This is despite the center of Edmonton showing the highest total volume of requests (Figure 5). It is noted that the city center is concentrated with businesses with few residences, and the disparities between the patterns of hot spots and total number of requests indicate that phone calls are possibly clustered at residential areas surrounding the city center; although the city center sees large number of requests, requests from the telephone channel are not significant. The cold spots of telephone requests are more significant than those of mobile app requests, and they are identified at the corners of the city, which also show a very low total number of requests (Figure $5)$. These areas are mainly covered by agriculture and undeveloped lands with a low population density (Figure 6), confirming that population plays an important role in the number of requests. However, it is observed that many of these colds spots are not similarly reflected in the mobile app requests, and even some hot spots are identified in these areas. From map (c) which represents hotspots of emails, the city center is identified as one of the hot spots. It is noted that the city center is not only concentrated with businesses, a significant number of institutions are also located in this area. The hot spots of web form reports (map (d)) shows that the two main industrial areas show some hot spots, implying that industrial areas have more use of web forms than other areas in the city. Overall, these hotspot results show the emergence of two different types of response patterns, driven by the type of technology used. One response pattern is that of the telephone-a traditional method of reporting information to municipal government. These patterns track major residential areas that have high population density. The other major pattern is generated by Internetenabled methods, namely mobile app, email, and web form. These channels of communication show clustering in a much smaller range of areas, many of which are industrial, institutional, or have otherwise low population densities.

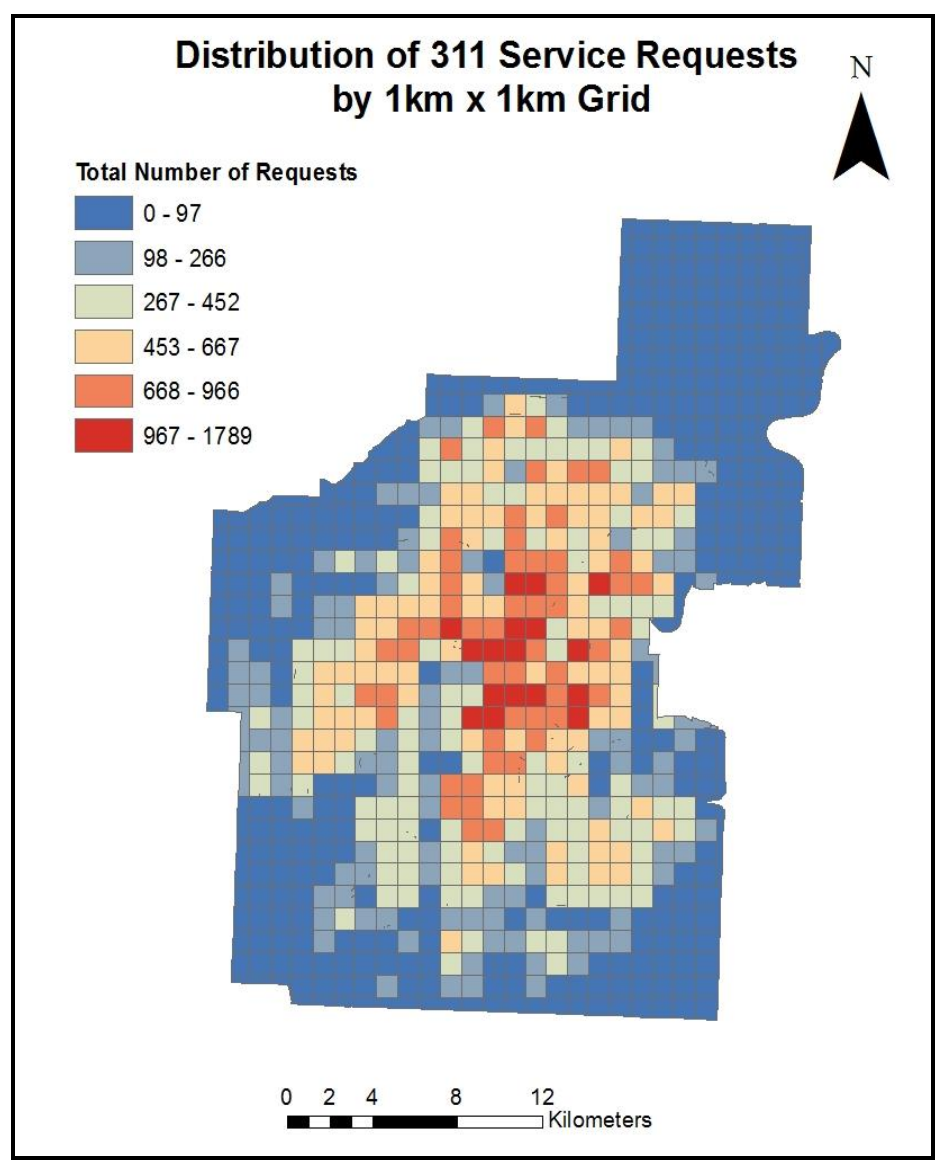

Figure 5. Distribution of service requests by $1 \mathrm{~km} \times 1 \mathrm{~km}$ grid. 


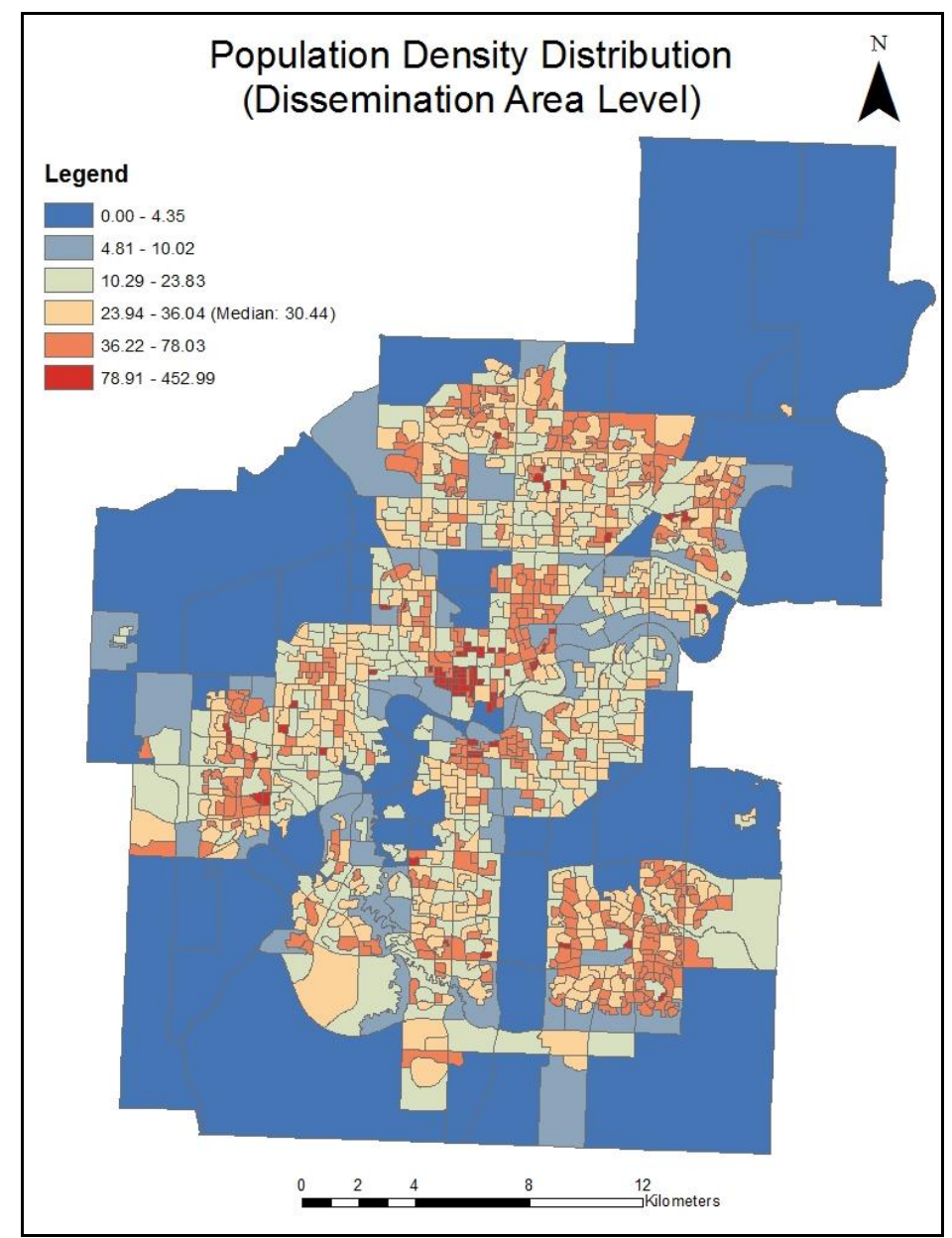

Figure 6. Population density distribution at dissemination area level. Note: Dissemination Area (DA) Level is defined as the smallest standard geographic area for which all census data are disseminated, typically with a population of 400 to 700 persons (Statistics Canada, 2015b).

\subsection{Socio-Demographic Data}

Inequality in access to information and communication technologies (ICTS) and gaps in knowledge and technical skills is termed as a digital inequality or digital divide (Kuk, 2003). An example of this inequality is how income and education level are found to be positively correlated with Internet adoption as individuals with higher income and education level tend to use the Internet more (Goldfarb \& Prince, 2008). In addition, gender and age are also considered to be related to the use of ICT, as young people and males use new technologies more than the elderly or females (Lin, 2013). This section of the case study investigates if demographic profiles also play a role in the use of specific 311 service channels in the City of Edmonton. Key variables studied, as suggested by previous research into the digital divide include male population, female population, population by single year, percentage of population by citizenship, percentage of first language spoken (English), household income, and percentage of population 15 years or over without certificate, diploma or degree (Bélanger \& Carter, 2009; Goodchild, 2007a; Thomas \& Streib, 2003). This socio- demographic data is retrieved from SimplyMap, a web application from Geographic Research Inc. that provides access to Canadian federal statistical data including various demographic, business and marketing variables (Geographic Research Inc., n.d.).

Mirroring a previous study of municipal 311 services by Cavallo et al. (2014), ordinary least squares (OLS) regression is used to explore the relationships between demographic characteristics and the number of 311 service requests from each channel. OLS is a technique used to model a single dependent variable with single or multiple explanatory variables (Hutcheson, 2011). For this analysis, five regression models are built, and the dependent variables are the total number of requests and number of requests from each channel respectively. The explanatory variables are demographic characteristics along with geographic characteristics (Table 2). All the independent variables are listed in the table below. It is noted that all variables are measured at DA level. The output statistics of the five models are compared, examining the differences and commonalities in the variables that are significant (Table 3). 
Table 2. Explanatory variables in regression models.

\begin{tabular}{ll}
\hline Geographic Independent Variables & Area of DA \\
& Road Length per Square Kilometers \\
\hline Demographic Independent Variables & Total Population \\
& Percentage of Population without Certificate, Diploma \\
or Degree & Percentage of Non-citizens \\
& Gender Ratio of Male Population to Female Population \\
& Percentage of English Speakers \\
& Median Age \\
& Average Household Income \\
\hline
\end{tabular}

Table 3. Coefficients of regression models.

\begin{tabular}{|c|c|c|c|c|c|}
\hline Variables & $\begin{array}{l}\text { Total Number } \\
\text { of Requests }\end{array}$ & $\begin{array}{l}\text { Number of } \\
\text { Requests from } \\
\text { Telephone Call } \\
\end{array}$ & $\begin{array}{l}\text { Number of } \\
\text { Requests from } \\
\text { Mobile App } \\
\end{array}$ & $\begin{array}{l}\text { Number of } \\
\text { Requests from } \\
\text { Web Forms } \\
\end{array}$ & $\begin{array}{l}\text { Number of } \\
\text { Requests from } \\
\text { Emails }\end{array}$ \\
\hline Total Population & $0.102634^{*}$ & $0.088636^{*}$ & $0.005125^{*}$ & $0.001697^{*}$ & $0.007404 *$ \\
\hline $\begin{array}{l}\% \text { of Population without } \\
\text { Certificate, Diploma or } \\
\text { Degree }\end{array}$ & -0.457164 & -0.244727 & $-0.078431 *$ & $-0.065716^{*}$ & $-0.079826 *$ \\
\hline$\%$ of Non-citizens & -0.574014 & $-0.581898^{*}$ & -0.001987 & -0.005855 & 0.014135 \\
\hline Gender Ratio & 2.770114 & 4.494308 & -1.054695 & -0.276356 & 0.135342 \\
\hline \% of English Speakers & 0.859569 & 0.833315 & -0.061903 & -0.088039 & $0.202950^{*}$ \\
\hline Median Age & $2.326921 *$ & $2.179165^{*}$ & 0.033151 & 0.054881 & $0.000001^{*}$ \\
\hline Average Household Income & -0.000081 & -0.000067 & -0.000008 & $-0.000009 *$ & 0.085558 \\
\hline Area & $0.000022 *$ & 0.000019* & $0.000001^{*}$ & $0.000001^{*}$ & $-0.000003^{*}$ \\
\hline $\begin{array}{l}\text { Road Length Per Square } \\
\text { Kilometers }\end{array}$ & $34.041707^{*}$ & $29.321637^{*}$ & 1.474301 & $2.269063^{*}$ & 1.216818 \\
\hline Adjusted R-squared & 0.511382 & 0.515259 & 0.348505 & 0.133248 & 0.464634 \\
\hline
\end{tabular}

Note: Gender Ratio represents the ratio of male population to female population.

The results of the five regression models are shown in Table 3, including coefficients and R-Squared values. The explanatory variables marked with asterisks indicate that the variables are statistically significant. The significance of variables is evaluated by using a $T$ test. In this test, the null hypothesis is that the explanatory variable is not effective in the models, and the $p$-value represents the probability of observing the effect in the sample data if the null hypothesis is true. P-values smaller than 0.05 indicate the statistical significance of the explanatory variable. The sign of a coefficient implies the type of relationships between the explanatory variable and the dependent variable. Positive signs indicate positive relationship, which means that the dependent variable grows when the explanatory variable increases.

In Table 3, it is observed that total population is significant in all the models and the coefficients are all positive. It can be concluded that DAs with larger populations observe more 311 requests, which is within expectations. The following discussion will not include this variable, with focus shifted on to other demographic characteristics. For the model developed with total number of requests (not broken down by channel), it is noted that only median age is identified as a significant demographic variable and is positive, which means that older people tend to make more 311 requests than younger people. For this variable, the model shows a high R-squared value of 0.511382 , indicating that about $51 \%$ of variance in the total number of requests at DA level can be explained by the selected explanatory variables.

Further insight into the relationship between 311 channel choice and demographic variables can be gained through analysis of each specific channel. For the number of requests from telephone calls, the analysis results are similar to the total requests model except that the percentage of non-citizens also shows statistical significance. The negative sign indicates a negative relationship between percentage of noncitizens and the number of requests from telephone calls, thus areas with a larger proportion of noncitizens have less 311 requests made using the telephone. Note that this could also show that non-citizens (those with citizenship status of permanent resident, landed immigrant, work visa, or refugee), make less requests than citizens or they tend to use other channels to reach a 311 service. For the mobile app model, it is observed that the education indicator (percentage of population without certificate, diploma or degree) 
plays an important role and has a negative effect. DAs with a larger proportion of people in possession of a certificate, diploma or degree have more requests from mobile apps. Other demographic characteristics do not show significance in this model. For the web forms model, education level and average household income are identified as significant variables. The relationship between education level and number of requests from web forms is the same as the one in the mobile app model; people with a certificate, diploma or degree tend to make more requests. Household income also has a negative relationship with the number of requests from the web form channel, indicating DAs with higher average household income have less 311 requests via a web form. It is noted that the R-squared value of 0.133248 in this model is much smaller than those in other models; only about $13 \%$ of the variances in the number of requests from this channel can be explained by the explanatory variables. Lastly, for the email reporting channel, education level, percentage of English speakers and median age all play important roles. The education level has the same type of relationship with the dependent variable as discussed in the previous models; people without certificate, diploma or degree have lower tendency to make requests. It is noted that the percentage of English speakers is only significant in this model and has a positive effect, showing that English speakers are more inclined to make requests via email than non-English speakers. In addition, the median age indicator shows that older people make more use of the email channel to make requests than younger people.

\section{Discussion and Conclusions}

This research presents a case study of the City of Edmonton, examining its provision of municipal 311 services through various channels. The four channels provided for 311 service are telephone, web form, email, and a mobile app. These channels are each characterized for their relative share of all 311 requests over a three-year period, their geographic hotspots, and also the connection between selected sociodemographic characteristics and contributions by channel type. Overall, these three methods of analysis are used to compare the VGI contributions of individuals, showing differences based on type, location, and connections to sociodemographic characteristics.

\subsection{Changing Channels of VGI Contribution}

The assessment of three years of City of Edmonton 311 data reveals a notable shift in the share of service requests by channel. As described in Figure 2, with the launch of a mobile app, between $10-20 \%$ of 311 requests were received through this manner. Though traditional telephone requests still dominate, it is un- known how many of these are made through fixed landlines compared to mobile phones. Regardless, this case study demonstrates a channel shift in 311 use from the traditional voice methods requiring one-toone interaction between citizen and municipal employee to what could be termed more passive forms of communication, with a range from $20-35 \%$ of all requests over the last year being made via a combination of mobile app, web form, and email (Figure 2). As shown in Figure 3, the total number of requests does not grow with the introduction of new channels but decreases notably over time, which confirms that there is a shift from the voice-based channel to the Internetbased channels. While it is difficult to draw a distinction between mobile uses and non-mobile uses (such as those contributions made 'in the field' when a respondent encounters an issue, compared to a request made from a fixed location, such as home or work), this shift in channel should demonstrate to government the importance of providing multiple channels for citizen input in any 311 system. For gathering municipallyrelated VGI in the city, multiple channels are needed, and also have the potential to be a worthwhile extension of the traditional telephone 311 system.

\subsection{Uneven Contribution of VGI}

The characterization of channels of contributors revealed a change from traditional telephone reporting to a greater reliance on Internet-based reporting. In conjunction with this shift, there were notable geographic differences between reports generated through specific channels. As demonstrated in Figure 4, traditional reporting methods, such as the telephone were overwhelmingly focused around areas of high residential density, excluding the city core and fringe areas of the city. This contrasted with reports from Internet-based methods, such as mobile app, web form and email that were focused on industrial areas with low residential density, and more peripheral residential areas. Additionally, this hotspot analysis showed that Internet-based methods showed more significant hotspots of activity, compared to a broader geographic range like that seen with the telephone channel. This phenomenon could indicate that Internet-based response channels are more mobile, and thus reflect reporting that is more immediate or in reaction to a particular type of experienced issue. For example, Internet-based response channels may be better placed to report issues that have just occurred, such as breakage, dead animal removal, or specific incidents. In this way, Internet-based response channels are reflective of the advantages often ascribed to VGI as being closer to an actual phenomenon, and more representative of lived experience (Goodchild, 2007a). This is a finding that requires further follow up, with a linking of type of issue, time of reporting to the reporting channel. 
This hotspot analysis also presents to municipal government feedback that may help to refine municipal activities around proactive service provision, such as identifying locations within the City of Edmonton that may considered as 'problem' locations. Again, further analysis that incorporates the specific type of request could be used to determine if areas can be characterized with recurring issues and if these issues have a spatial nature to them. For example, if one road is the frequent site of dead animal removal, it may be prudent for municipal staff to investigate the potential of create safe road crossing environments for wildlife, or for posting signs to warn motorists of the potential danger. Spatial analysis of 311 requests also has the ability to be used to identify hotspots of channel usage and related gaps. For example, as mobile app diffusion accelerates, government can use 311 request channels to assess the relative merits to continued maintenance of legacy channels, as well as to target specific location-based campaigns or follow-up citizen services.

\subsection{Channel-Based Digital Inequalities}

A critical component to understanding 311 service requests is to attempt to match requests to contributor profiles. Given the absence of personally-identifying information in 311 request information, requests are matched with sociodemographic data for the DA unit of statistical analysis. This analysis makes a major assumption in that requests are made by individuals who are living in the same place as where the request was made. Similar research, such as that by Cavallo (2014) does not expressly consider this limitation imposed by the size of the statistical areas and the mobile nature of requests. In this study, there are several interesting connections between sociodemographic characteristics and the channel of 311 service request. These connections can be interpreted as showing the presence of digital divides that are based on channel usage. The most notable of these is the link between median age and channel usage. As indicated in Table 3, median age is identified as a significant variable in the phone call requests, indicating that older people have a higher tendency to make requests via telephone than younger people. Additionally, education level plays an important role in mobile app, web form and email models but not in telephone calls. This implies that requests from the three channels are more likely to be made by people with certificate, diploma or degree. Some researchers pointed out that there is a significant gap in the use of new technologies between male and female groups. For example, Wilson, Wallin and Reiser (2003) suggested that women are much less likely to own and use computers than men based on a survey in North Carolina. Additionally, Liff, Shepherd, Wajcman, Rice and Hargittai (2004) argued that the divide between men and women exists not only in whether adopting the technology but also in the purpose of the technology use. However, gender is not identified as a significant factor in the use of 311 channel in this study. One of the reasons could be the increasing penetration and availability of the Internet that contribute to the narrowing gap in terms of technology access and adoption between genders (Dholakia, 2006).

\subsection{Limitations of the Analysis}

There are several areas of limitation in this paper. First, the request data obtained from the City of Edmonton covers a short time period compared to the total lifespan of the 311 service. The 311 service was started in December 2008 while the 311 request data used in this study was from January 2013 to December 2015. Therefore, the number of requests received from December 2008 to December 2012 and the channel distribution of the requests is not analyzed and interpreted. The trend of use of multiple channels presented in this paper would be more complete if the request data before January 2013 was available. Second, all the socio-demographic data such as percentage of noncitizens used in this study is based on the Canadian data from the 2011 National Household Survey, which was not an official census, but rather a voluntary survey. This data from 2011 may not reflect the sociodemographic profile of the request data, due to a 2 to 4 year gap between them. Therefore, the relationships between the use of channel and demographic characteristics identified in this paper could contain some bias. In addition, it is noted that the relationships between use of different 311 channels and demographic variables are analyzed based on aggregated data at DA level, assuming requests observed in a DA is made by the residents of this area. However, in the real world, people are travelling instead of staying at one place all the time; it is likely that a request is submitted by a person who lives in other areas. Although some DAs such as industrial areas that recorded a large number requests and very low population density have been removed in the regression analysis, the results would still have some uncertainties due to the mobility of residents.

\subsection{Traditional vs. Internet-Based 311 Reporting Channels}

Municipal 311 services provide a valuable way for citizens to connect with government, creating a conduit for the reporting of non-emergency issues. As the technologies used to provide 311 services have changed from traditional to Internet-based, it should come as no surprise that the patterns and nature of citizen reporting have also changed. As one of Canada's most 'open' cities, Edmonton provides a case study of 311 channel use, and tracks this change from tradition- 
al forms, such as the telephone, to a mixed 311 system involving mobile apps, web forms, and email. The differences between these two broad categories (traditional and Internet-based) are striking, with distinct spatial patterns, and connections to demographic characteristics. As a traditional method, telephone service requests largely match residential areas, and favor older individuals. Comparably, Internet-based service requests are more focused on specific areas outside of heavily populated areas, and favor younger individuals. The demographic characteristics play an important role in the use of 311 service channels, and their relationships are distinct for different channels. Education level is significantly related to the use of the Internet-based channels, and higher education level is associated with more requests from the Internet-based channels; however, education level is not significant in the number of requests from telephone calls. Citizenship status is another variable that is different between the two categories of channels; percentage of non-citizens is identified significantly related to the number of requests from telephone calls, but this variable shows no significance in the requests from the Internet-based channels. It is observed that telephone call requests decrease with increases in the percentage of non-citizens. In both instances, these service requests represent a form of $\mathrm{VGI}$-these are asserted, geographicallyexplicit requests from citizens for a service from their government. Future work on these topics should focus on characterizing the users of municipal 311 based on their contributions. For example, are there repeated requests made by a core group of contributors? Are there specific areas and types of requests that are repeated or are there areas that are not reported? Important work remains on assessing the constraints to government adoption of requests, including a tracing of how different channels of service request are treated from within government. For example, is there preference given to a particular channel? Additionally, what is the impact of service requests made from outside the official 311 system using social media to connect with municipal or elected staff? As technologies advance the channels available for citizens to generate VGI and connect with their government, it opens up new questions, including the assessment of these systems, as well as considerations of who is favored and who may be left behind by these technological changes.

\section{Acknowledgments}

The authors thank everyone in Geospatial Innovation Lab at the University of Waterloo for their comments and advice on the data analysis process. We also acknowledge the support of Geothink, a Canadian geospatial and open data research partnership funded by the Social Sciences and Humanities Research Council of Canada (SSHRC).

\section{Conflict of Interests}

The authors declare no conflict of interests.

\section{References}

Bélanger, F., \& Carter, L. (2009). The impact of the digital divide on e-government use. Communications of the ACM, 52(4), 132-135.

Brown, G. (2012). Public participation GIS (PPGIS) for regional and environmental planning: Reflections on a decade of empirical research. Journal of Urban and Regional Information Systems Association, 25(2), 718.

Brown, G., \& Kyttä, M. (2014). Key issues and research priorities for public participation GIS (PPGIS): A synthesis based on empirical research. Applied Geography, 46, 122-136.

Cavallo, S., Lynch, J., \& Scull, P. (2014). The digital divide in citizen-initiated government contacts: A GIS approach. Journal of Urban Technology, 21(4), 77-93.

Chon, J., \& Cha, H. (2011). Lifemap: A smartphone-based context provider for location-based services. IEEE Pervasive Computing, (2), 58-67.

City of Edmonton. (n.d.). Open data portal. City of Edmond. Retrieved from https://data.edmonton.ca/ apps/311explorer

Coleman, D. J., Georgiadou, Y., \& Labonte, J. (2009). Volunteered geographic information: The nature and motivation of produsers. International Journal of Spatial Data Infrastructures Research, 4(1), 332-358.

Compaine, B. M. (2001). The digital divide: Facing a crisis or creating a myth? Cambridge, MA: MIT Press.

Cooper, A. K., Coetzee, S., Kaczmarek, I., Kourie, D. G., Iwaniak, A., \& Kubik, T. (2011). Challenges for quality in volunteered geographical information. Cape Town, South Africa: AfricaGEO.

DeMeritt, M. (2011). Simplifying citizen reporting. ArcUser, Magazine for ESRI Software User, 14(1), 2627.

Dholakia, R. R. (2006). Gender and IT in the household: Evolving patterns of internet use in the United States. The Information Society, 22(4), 231-240.

Elwood, S., Goodchild, M. F., \& Sui, D. Z. (2012). Researching volunteered geographic information: Spatial data, geographic research, and new social practice. Annals of the association of American geographers, 102(3), 571-590.

Esri. (2015). How hot spot analysis (Getis-Ord Gi*) works. ArcGIS for Desktop. Retrieved from http:// pro.arcgis.com/en/pro-app/tool-reference/spatialstatistics/h-how-hot-spot-analysis-getis-ord-gi-spatial -stati.html

Ganapati, S. (2010). Public participation geographic information systems: A literature survey. In C. G. Reddit (Ed.), Comparative e-government (pp. 449-466). New York: Springer. 
Ganapati, S. (2011). Uses of public participation geographic information systems applications in e-government. Public Administration Review, 71(3), 425-434.

Genovese, E., \& Roche, S. (2010). Potential of VGI as a resource for SDIs in the North/South context. Geomatica, 64(4), 439-450.

Geographic Research Inc. (n.d.). A little about us. SimplyMap. Retrieved from http://geographicresea rch.com/simplymap/about-us/

Goldfarb, A., \& Prince, J. (2008). Internet adoption and usage patterns are different: Implications for the digital divide. Information Economics and Policy, 20(1), 2-15.

Goodchild, M. F. (2007a). Citizens as sensors: The world of volunteered geography. GeoJournal, 69(4), 211221.

Goodchild, M. F. (2007b). Citizens as voluntary sensors: Spatial data infrastructure in the world of web 2.0. International Journal of Spatial Data Infrastructures Research, 2, 24-32.

Goodchild, M. F., \& Glennon, J. A. (2010). Crowdsourcing geographic information for disaster response: A research frontier. International Journal of Digital Earth, 3(3), 231-241.

Goodchild, M. F., \& Li, L. (2012). Assuring the quality of volunteered geographic information. Spatial statistics, 1, 110-120.

Haklay, M. (2013). Citizen science and volunteered geographic information: Overview and typology of participation. In D. Z. Sui, S. Elwood, \& M. F. Goodchild (Eds.), Crowdsourcing geographic knowledge (pp. 105-122). Netherlands: Springer.

Hall, G. B., Chipeniuk, R., Feick, R. D., Leahy, M. G., \& Deparday, V. (2010). Community-based production of geographic information using open source software and Web 2.0. International journal of geographical information science, 24(5), 761-781.

Hutcheson, G.D. (2011). Ordinary least-squares regression. In L. Moutinho \& G. D. Hutcheson (Eds.), The Sage dictionary of quantitative management research (pp.224-228). Los Angeles, CA: SAGE.

Jiang, B., \& Yao, X. (2006). Location-based services and GIS in perspective. Computers, Environment and Urban Systems, 30(6), 712-725.

Johnson, S. (2010). What a hundred million calls to 311 reveal about New York. WIRED. Retrieved from http://www.wired.com/2010/11/ff_311_new_york/ all/1

Johnson, P. A., \& Sieber, R. E. (2013). Situating the adoption of VGI by government. In D. Z. Sui, S. Elwood, \& M. F. Goodchild (Eds.), Crowdsourcing geographic knowledge (pp. 65-81). Netherlands: Springer.

Kuk, G. (2003). The digital divide and the quality of electronic service delivery in local government in the United Kingdom. Government Information Quarterly, 20(4), 353-363.
Liff, S., Shepherd, A., Wajcman, J., Rice, R., \& Hargittai, E. (2004). An evolving gender digital divide? Oll Internet Issue Brief, (2). Oxford: Oxford Internet Institute. Retrieved from http://papers.ssrn.com

Lin, W. (2013). When web 2.0 meets public participation GIS (PPGIS): VGI and spaces of participatory mapping in China. In D. Z. Sui, S. Elwood, \& M. F. Goodchild (Eds.), Crowdsourcing geographic knowledge (pp. 83103). Netherlands: Springer.

Moon, M. J. (2002). The evolution of e-government among municipalities: Rhetoric or reality? Public administration review, 62(4), 424-433.

Naphade, M., Banavar, G., Harrison, C., Paraszczak, J., \& Morris, R. (2011). Smarter cities and their innovation challenges. Computer, 44(6), 32-39.

Offenhuber, D. (2014). Infrastructure legibility: A comparative analysis of open 311-based citizen feedback systems. Cambridge Journal of Regions, Economy and Society CAMRES, 8(1), 93-112.

Rinner, C., Keßler, C., \& Andrulis, S. (2008). The use of Web 2.0 concepts to support deliberation in spatial decision-making. Computers, Environment and Urban Systems, 32(5), 386-395.

Sæb $\varnothing, \varnothing .$, Rose, J., \& Flak, L. S. (2008). The shape of eparticipation: Characterizing an emerging research area. Government information quarterly, 25(3), 400428.

Schwester, R. W., Carrizales, T., \& Holzer, M. (2009). An examination of municipal 311 system. International Journal of Organization Theory and Behavior, 12(2), 218-236

Scott, L., \& Warmerdam, N. (2005). Extend crime analysis with ArcGIS spatial statistics tools. Esri. Retrieved from http://resources.arcgis.com/en/communities/ analysis/017z00000015000000.html

Sieber, R. E., \& Johnson, P. A. (2015). Civic open data at a crossroads: Dominant models and current challenges. Government Information Quarterly, 32(3), 308315.

Statistics Canada. (2015a). Estimates of population by census metropolitan area, sex and age group for July 1 , based on the Standard Geographical Classification (SGC) 2011(CANSIM Table 051-0056). Statistics Canada. Retrieved from http://www5.statcan.gc.ca/ cansim/a26?lang=eng\&retrLang=eng\&id=0510056\& \&pattern $=\&$ stByVal=1\&p1=1\&p2=37\&tabMode $=$ data Table\&csid=

Statistics Canada. (2015b). Dissemination area. Statistics Canada. Retrieved from https://www12.statcan.gc. ca/census-recensement/2011/ref/dict/geo021-eng.c $\mathrm{fm}$

Sui, D., Goodchild, M., \& Elwood, S. (2013). Volunteered geographic information, the exaflood, and the growing digital divide. In D. Z. Sui, S. Elwood, \& M. F. Goodchild (Eds.), Crowdsourcing geographic knowledge (pp. 1-12). Netherlands: Springer.

Thomas, J. C., \& Streib, G. (2003). The new face of gov- 
ernment: Citizen-initiated contacts in the era of egovernment. Journal of public administration research and theory, 13(1), 83-102.

Tulloch, D. L. (2008). Is VGI participation? From vernal pools to video games. GeoJournal, 72(3-4), 161-171.

Turner, A. (2006). Introduction to neogeography. Retrieved from http://highearthorbit.com/neogeogra phy/book.pdf

West, D. M. (2004). E-government and the transfor- mation of service delivery and citizen attitudes. Public Administration Review, 64(1), 15-27.

Wilson, K. R., Wallin, J. S., \& Reiser, C. (2003). Social stratification and the digital divide. Social Science Computer Review, 21(2), 133-143.

Wong, W., \& Welch, E. (2004). Does e-government promote accountability? A comparative analysis of website openness and government accountability. Governance, $17(2), 275-297$.

\section{About the Authors}

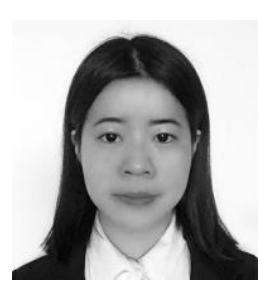

Qing Lu is a master student in the Geography and Environmental Management Department at the University of Waterloo. She obtained Bachelor of Science in Environmental Studies at Nanjing University in China and Bachelor of Environmental Science with Geomatics Specialization at the University of Waterloo in Canada. Her research interests include e-government, volunteered geographic information and geospatial technologies in planning and decision-making.

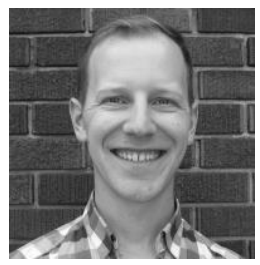

Peter A. Johnson (PhD) is an assistant professor in the Department of Geography and Environmental Management at the University of Waterloo. His research seeks to understand how governments, citizens, and private companies share information through geospatial technology, including open data, the geoweb, social media, mobile devices, and the process of crowdsourcing. 